stellte sich heraus, dass die Hauptmenge aus Trinitrotoluol (rotgelb reagierend) mit ganz geringen, als Verunreinigung vorhandenen Mengen 1, 2, 4 Dinitrotoluol bestand, das nach der Reinigung tatsächlich die rein blaue Farbenreaktion ergab. Das Trinitroprodukt wurde durch den Schmelzpunkt identifiziert. Dieser Fall und noch einige andere, einfachere zeigten, dass die vorgenannten Reaktionen geeignet sein dürften, die qualitative Untersuchung von Sprengstoffen erheblich zu erleichtern. Es wäre daher vielleicht wünschenwert, dass von anderer Seite diese Reaktionen nachgeprüft und auf eine Reihe weiterer Nitroprodukte ausgedehnt würden, da für mich selbst die Möglichkeit hierzu nicht mehr besteht.

\begin{tabular}{|c|c|c|c|c|}
\hline Bezeichnung & $\begin{array}{l}\text { Alkoholische } \\
\text { Lösung } \\
\text { mit } \mathrm{NaOH}\end{array}$ & $\begin{array}{c}\text { Azetonlösung } \\
\text { mit } \\
\mathrm{NaOH}\end{array}$ & $\begin{array}{c}\text { Alkoholische } \\
\text { Lösung } \\
\text { mit } \mathrm{NH}_{3}\end{array}$ & $\begin{array}{l}\text { Azetonlösung } \\
\text { mit } \mathrm{NH}_{3}\end{array}$ \\
\hline o-Dinitrobenzol & farblos & (kalt) farblos & farblos & farblos \\
\hline $\mathrm{m}^{\circ}$-Dinitrobenzol . & farblos & $\begin{array}{l}\text { intensiv rot- } \\
\text { violett }\end{array}$ & farblos & $\begin{array}{l}\text { rosenrot bis } \\
\text { purpur }\end{array}$ \\
\hline p-Dinitrobenzol . . & farblos & intensiv gelb & $\begin{array}{l}\text { keine charak- } \\
\text { terist. Färbung }\end{array}$ & blassgelb \\
\hline 1,3,5 Trinitrobenzol & intensiv gelbrot & blutrot & gelbrot & blutrot \\
\hline 2,4 Dinitrotoluol . . & tiefblau & tiefblan & farblos & farblos \\
\hline 2, 6 Dinitrotoluol . . & farblos & $\begin{array}{l}\text { ajlmählich } \\
\text { schwach rosenrot }\end{array}$ & farblos & farblos \\
\hline 2, 4, 6 Trinitrotoluol & tief gélbrot & $\begin{array}{l}\text { weinrot his } \\
\text { purpurrot }\end{array}$ & hellrot & hellrot \\
\hline 1, 8 Dinitronaphtalin ${ }^{1}$ ) & gelbrot & gelbrot & rötlich & rötlich \\
\hline
\end{tabular}

Notiz über die Bestimmung des Nickels und Kupfers anf vernickelten oder verkupferten Eisenwaren. von

H. Koelsch.

Die Bestimmung des Nickels und Kupfers auf Eisenwaren war bisher umständlich, da die bekannten Lösungsmittel für diese Metalle auch Eisen lösen. Neuerdings (H. Koelsch D. R. P. 319855 und 330131 ) wurde festgestellt, dass metallisches Eisen durch Nitrit-Ion in

1) Kaum löslich. 
neutraler Lösung und in Lösungen, die $\mathrm{H}^{*}$-Ionen in geringer Konzentration enthalten, passiv wird. Diese Eigenschaft des Eisens erlaubt, in salpetriger Säure lösliche Überzugsmetalle von Eisen abzulösen. Ein geeignetes Lösungsmittel ist beispielsweise eine mit Essigsäure angesäuerte heisse Natriumnitritlösung. So lange noch Nitrit-Ionen vorhanden sind, wird das Eisen von der Säure nicht angegriffen, wodurch eine unangenehme Trennungsoperation gespart wird.

Die Bestimmung des Phosphors in Eisen, Stahl, Erzen und Schlacken ${ }^{1}$ ). Von

\section{H. Kinder.}

Der Chemikerausschuss des Vereins Deutscher Eisenhüttenleute hat durch seinen Arbeitsausschuss die Verfahren zur Phosphorbestimmung in den oben genannten Fällen einer kritischen Prüfung unterworfen und sich dabei ausschliesslich auf die Wägung des Molybdänniederschlags beschränkt, weil bei den kleinen Phosphormengen die Wägung als Magnesiumpyrophosphat zu ungenau ist.

Von den gewichtsanalytischen Methoden können nur in Betracht kommen: 1. Das Trocknen des gelben Molybdänniederschlags bei $105^{\circ}$ nach Finkener ${ }^{2}$ ) und 2. das Glühen des gelben Niederschlags bei etwa $450^{0}$ nach $\mathrm{Meine \textrm {ke }}{ }^{3}$ ).

An 8 verschiedenen Arbeitsstellen wurden nach einheitlichem Plan die nachstehend beschriebenen Arbeiten ausgeführt.

Die zu den Versuchen benutzte Ammoniummolybdatlösung wurde gleichmäßsig hergestellt durch Lösen von $50 \mathrm{~g}$ Ammoniummolybdat in $200 \mathrm{ccm}$ Ammoniak von 0,96 spez. Gew.. Diese Lösung wurde vorsichtig eingetragen in $750 \mathrm{ccm}$ Salpetersäure von 1,2 spez. Gew. Nach mebrtägigem Stehen wurde die Lösung vor der Benutzung filtriert.

Nach Verfahren 1 erfolgt die Wägung des gelben Niederschlages am besten auf gewogenem Asbest-Glaswolle-Filter.

Die mitgeteilten Ergebnisse der einzelnen Versuchsstellen sind Durchschnittswerte von zahlreichen Einzelversuchen, können also als zuverlässig angesprochen werden.

Die erste Aufgabe bestand darin, die Faktoren für den Phosphorgehalt der Molybdänverbindungen beider Verfahren (nach Finkener

1) Auszügliche Wiedergabe des Berichtes des Chemikerausschusses 1 des Vereins Deutscher Eisenhüttenleute (Stah] und Eisen, 192), S. 381 und 468), vorgetragen in der Fachgruppe für analytische Chemie des Vereins Deutscher Chemiker bei der Hauptversammlung 1920.

2) Ber. Deutsch. Chem. Ges. 11, 1638 (1878); vergl. diese Ztschrft. 21, $566,(1882)$.

3) Chem. Ztg. 20, 108 (1896); vergl. diese Ztschrft. 46, 374 (1907).

Fresenius, Zeitschrift f. anal. Chemie. LX. 7. n. 8. Heft. 